\title{
Project-Based Learning on Teaching Communications Circuits
}

DOI: 10.37702/2175-957X.COBENGE.2021.3614

Antonio Luiz Pereira de Siqueira Campos - alpscampos@gmail.com UFRN

Av Sen Salgado Filho, s/n, Lagoa Nova, Campus Central S/N

59078-970 - Natal - RN

Marcio Eduardo da Costa Rodrigues - marcio.rodrigues@ct.ufrn.br Universidade Federal do Rio Grande do Norte Avenida Capitão-mor Gouveia 2488 59070-400 - Natal - RN

Mailson Rodrigues de Medeiros Guimarães - 1997.rodriguez@gmail.com Universidade Federal do Rio Grande do Norte Rua Ex-Combatente Jaime da Silva 26 59014-680 - Natal - RN

Cefas Rodrigues Freire - cefas@ufrn.edu.br Universidade Federal do Rio Grande do Norte Rua Manoel Firmino 64 59675-000 - Grossos - RN

José Arilton Pereira Filho - arilton.japf@gmail.com UFRN

R. Adeodato José dos Reis 595

59152-820 - Parnamirim - RN

Leidiane Carolina Martins de Moura Fontoura - leidiane.c2m@gmail.com Universidade Federal do Rio Grande do Norte Rua Claudionor de Andrade 340 59075-350 - Natal - RN

Resumo: The paper presents the project of a curriculum for the Communications Circuits course implementing Project-Based Learning (PBL) as instructional methodology to stimulate students to incorporate research for problem-solving in their course activities. The proposal, aligned to the new Brazilian national 
curriculum guidelines for Engineering, immerses students in problem-solving cases and focuses patterns which reflect the emphasis nowadays stablished in the developing of competences and in mastering the course contents, evidencing the learning success. Herein, it is presented the methodology itself and reports of achieved results, comparing data from classes following traditional learning methodologies with the ones in which PBL was used.

Palavras-chave: Project-Based Learning, PBL, Communications Circuits, Circuits for Communications. 


\section{PROJECT-BASED LEARNING ON TEACHING COMMUNICATIONS CIRCUITS}

\section{$1 \quad$ INTRODUCTION}

Recent studies point out to the need of changes in engineering teaching, in order to stimulate in the graduates: a better understanding of the human, social and cultural conditions; the capacity of working on public policies, business and government; the comprehension of the whole innovation process and of its contributing factors; the ability of working with people coming from different fields in science and engineering; and the capacity of explaining technical issues in simple and understandable words to the noninitiated (KING, 2012; ORTIZ and LEIFFER, 2008; COSTA et al., 2007).

The Future of Jobs report, from the World Economic Forum, points out to important modifications in the industrial segment hiring for the next years, with the advent of the Industry 4.0 (WORLD ECONOMIC FORUM, 2016). There is an increasing demand for transversal competences. Therefore, a proper adequation of universities is essential to prepare their students for the new industrial scenery.

Due to the evolution in the desired engineer profile, traditional education methodologies are no longer being considered as efficient (PRINCE and FELDER, 2006). Consequently, schools and universities are searching for new ways to develop necessary competences and abilities in their students. The adoption of active learning methodologies allows students to leave the position of mere spectators, pursuing a role of true leadership in their learning process (MULONGO, 2013).

$\mathrm{PBL}$ is an active learning methodology which consists in the developing of projects based on real-life problems throughout the academic semester. The goal is to make students enhance knowledge and abilities necessary to the application of the theory (ECHAVARRIA, 2010).

This methodology proposes to make students face real and tangible problems, with different degrees of difficult. Solutions have an appropriate time to be executed and require previous theoretical knowledge from the class. In addition, students must use their understanding of different technical disciplines, integrating knowledge - since real world problems are interdisciplinary ones -, besides searching for new knowledge from numerous available sources (LEHMANN et al., 2008).

In Brazil, the Ministry of Education (MEC) published, in April 2019, the new National Curricular Guidelines (DCNs) for the Engineering graduation courses. According to the report emitted by the National Education Council (CNE), these new guidelines intend to comply with future demands for more and better engineers (MINISTRY OF EDUCATION, 2009).

This paper reports the experience gained by means of a PBL pilot project, applied in the Communications Circuits discipline, which is compulsory in the context of the Telecommunications Engineering graduation course, in the Federal University of Rio Grande do Norte (UFRN). It is shown the curricular development and the evolution of key performance indexes of classes in a period of four years. 


\section{PREVIOUS RELATED WORKS}

BRUCE et al. (2004) proposed an experimental cooperative learning activity based on an embedded systems project. The PBL approach is adopted, allowing the students to design, build and solve problems as a team. It consists of a progressive project of a micro controller composed by embedded systems peripherals common to the industry. In a progressive fashion, each new designed subsystem is incorporated to the existent ones. The goal is to convey necessary technical abilities and to develop professional competencies, exposing the student to a realistic environment with practical situations found in industry.

HERNANDEZ-JAYO et al. (2015) described the use of PBL in four compulsory disciplines: Communications Circuits Design, Electronical Instrumentation, Advanced Signal Processing Systems and Radiocommunication Systems. The educational project consists of the manufacturing of a Doppler radar using continuous wave frequency modulation, built from basic, simple, and low-cost components. The goal is to put engineers in the market which are ready to perform as trained and competent professionals, with the ability to design, develop and integrate telecommunication systems and knowing how systems respond to different situations.

PRICE et al. (2010) worked on the implementation of a strategy of PBL in which projects are executed by teams. In this approach, disciplines are organized in learning unities associated to collaborative projects which encompass, simultaneously, many fields like Robotics (including competition), Digital and Analog Electronics, Sensors, Measurement Instruments, Computing, Communication, Project Management and Technical Presenting. Furthermore, the required competencies needed to form and to credit professionals by regulatory entities are segmented in activities to be developed during the execution of the projects by the students.

SOTO-CAMPOS (2012) described the use of PBL in a course on digital microelectronics held by the Telecommunication Engineering School, located in the Vigo University, Spain. The paper depicts the methodology itself, explaining the way it is applied and which characteristics can be developed by the students through the application of the methodology, for instance, problem solving and decision-making skills. At the end, details are given about the success rate of the students.

MCLOONE et al. (2014) described the first implementation of PBL in the National University of Ireland Maynooth (NUIM). The chosen theme was the project of electrical circuits for first year students. The methodology and its benefits were presented, as well as the enhancements in learning, the interdisciplinary knowledge, the collective work, conflicts solving and the development of: a professional identity, responsibilities and competencies, like the management of a project.

AAS and TYPPO (1999) presented a PBL approach for use in the Digital Electronics Design discipline, in the Norwegian University of Science and Technology, Norway, in 1997. A research was conducted among 751 engineers and 100 industrial managers for the construction of the curricular programs. Class works were done by teams and peer evaluation was performed afterwards. Groups exchanged their reports and evaluated themselves according to criteria previously defined by the professor, in two different moments. Afterwards, a third report was elaborated containing necessary corrections and then the final work was orally presented. Eventually, a written evaluation was applied to check if the desired competencies were developed.

NORTHERN (2007) presented the proposal of a curriculum adopting PBL in the teaching of Field-programmable Gate Array (FPGA), searching for fast FPGA based prototyping. In this context, students learned how to program and to design using high-level 
Hardware Description Language (HDL). The authors remark that PBL demands from the students, critical knowledge, proficiency in the solution of problems, self-directing learning strategies and teamwork skills. Besides, it is also shown how this approach motivated students to engage in the learning process.

LIDDICOAT et al. (2008) described modifications done in the curricular base of engineering courses to accommodate learning objectives which better prepare students for the PBL approach. The following competencies were included: Computer Aided Design (CAD) tools, Printed Circuit Board (PCB) design, project for manufacture, electronic assembly, project management, ethics applied to engineering and communication. Courses were split into two phases. In the first one, a learning module was offered to give students experience in design, manufacturing, and test of PCB systems. The second one was composed by a PCB Electronic Design course and CAD tools.

In the present work, experiences in the application of PBL methodology in the Communications Circuits discipline are presented. It is a 60-hour course, taught along a semester, mandatory in the Telecommunications Engineering course of the Federal University of Rio Grande do Norte and having Fundamentals of Electronics as pre-requisite.

\section{ADOPTED METHODOLOGY}

The objective of the proposed curriculum project comes from the academic perspective of using the PBL approach to enhance the learning process and to improve the retention of material teach in theorical classes. This perspective can help reaching the following objectives: (1) to produce laboratory practices aiming to consolidate theorical concepts; (2) to connect the theory-based learning to real life applications; (3) to improve the technical material documentation for future classes of the course; (4) to enhance the laboratory skills of the students; and (5) to improve confidence and attitude of students towards their future profession.

The methodology begins with the split of the class into teams of four students each, in such a way that half the class will implement a frequency modulation (FM) transmitter and the other half will build a FM receiver. This split occurs at the first week of the course.

The projects have a certain amount of complexity to aid in the cooperative learning, in such a way that it is stablished an interdependency among the members of each team. The attribution of activities to the team members is a task of the team manager, named by the professor. The manager must administrate, besides the individual tasks, the evaluations of each team member.

Each project is divided in six blocks, with gradual increase in the difficulty. Some theorical classes are taught, explaining how each block works, to help the teams in the developing of their project.

There are four evaluation dimensions: presentation of the developed projects, technical reports, individual performance, and team evaluation. Through the presentation of developed projects, it is analyzed the participation of each student regarding his/her performance in the laboratory. Technical reports must be delivered after the conclusion of each block, then there are six reports in total. Individual performance is evaluated from the participation of the student in the classes and his/her performance in the laboratory. Finally, the team evaluation is performed by the manager of each group. 


\section{FM TRANSMITTER}

The transmitter is composed by six blocks, according to the diagram pictured in Figure 1. The six transmitter blocks are: oscillator, to generate a sinusoidal modulating signal; passive low-pass filter; voltage-controlled oscillator (VCO); signal pre-amplifier; passive band-pass filter; and a power amplifier.

The projects were planned in such a way that the level of difficulty increases along the implementation of the blocks, so that students develop more skills in a progressive fashion. Furthermore, specifications of each block are changed each semester, avoiding copies.

The first designed and implemented block is a low frequency and low amplitude amplifier. The circuit in this block must provide a modulated signal in its output with a minimum amplitude of $1 \mathrm{~V}$. The sinusoidal input wave oscillates at $5 \mathrm{kHz}$ and the input amplitude may vary from $200 \mathrm{mVpp}$ to $1 \mathrm{Vpp}$. In this block, students must measure input and output signal-to-noise ratio and then calculate the amplifier noise figure.

The second block is the circuit of a power amplifier using Field Effect Transistor (FET). It must have a minimum gain of tension of 4 . Students must measure the Minimum Detectable Signal (MDS) and the Input-Referred 3rd order Intercept Point (IIP3), then determining the dynamic range of the circuit.

The third block is a passive low-pass filter having attenuation of $60 \mathrm{~dB} /$ decade. Students must measure $|\mathrm{S} 21|$ as a function of frequency. The project is open, allowing the use of RC circuits in the implementation.

The fourth block is a passive band-pass filter using series or parallel RLC circuit. As an example, it can be demanded quality factor of 5 and center frequency of $250 \mathrm{kHz}$. Students must measure $|\mathrm{S} 21|$ as a function of frequency.

The fifth block is an harmonic oscillator which must deliver a sinusoidal output wave oscillating at $5 \mathrm{kHz}$ and minimum amplitude of $200 \mathrm{mVpp}$. Students must measure the Total Harmonic Distortion (THD).

Eventually, the teams responsible for the implementation of FM transmitters must build a VCO (sixth block), indirect or digital type, according to the project specification. At this last phase, students measure the modulation index, the constant of the modulation circuit and the modulated signal bandwidth.

Figure 1 - FM transmitter blocks diagram.

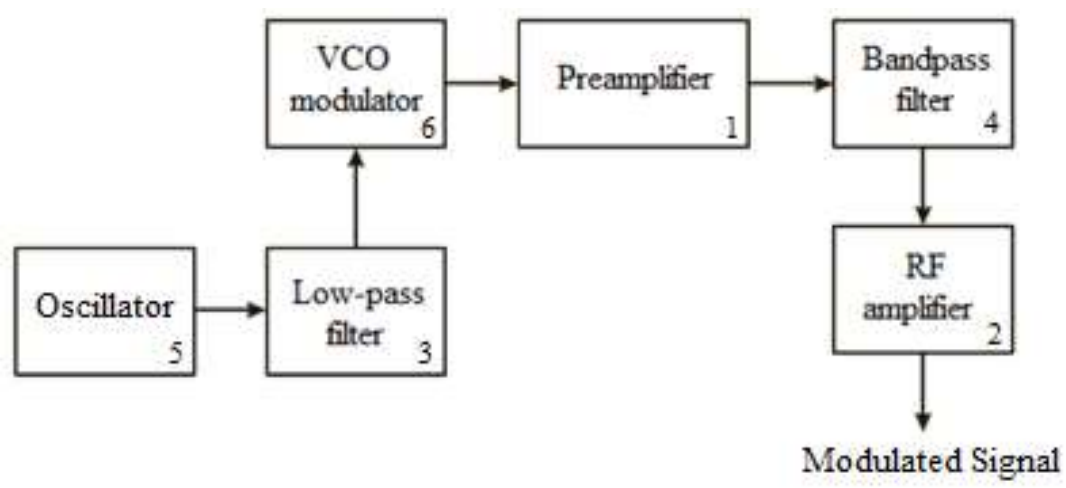

Source: created by the authors (2020). 


\section{FM RECEIVER}

The receiver is also composed by six blocks, to keep the equity of task among the groups. The blocks diagram is illustrated in Figure 2. The six blocks are: mixer; local oscillator; band-pass filter; pre-amplifier; FM demodulator; and audio amplifier.

As it was done for the transmitter, the projects were planned in such a way that the level of difficulty increases along the implementation of the blocks, allowing students to develop more skills progressively.

The first designed and implemented block is the pre-amplifier, which must amplify the intermediate frequency (IF) signal obtained from the band-pass IF filter output, delivering an output signal with amplitude ranging from $1 \mathrm{~V}$ to $5 \mathrm{~V}$. Students have to measure input and output signal-to-noise ratio and then calculate the pre-amplifier noise figure.

The second block consists of the audio amplifier, which has to be transistorized and must deliver a minimum gain of tension of 5 . The figure of merit to be computed here is the same as the one in the first block, the noise figure.

The third block is a band-pass IF filter having quality factor of 0,5 , with open design and implementation (active filter can be used). Students must measure |S21| as a function of frequency.

The fourth block in an harmonic oscillator responsible for the generation of the local carrier, to help reaching the IF frequency. Students must measure harmonic distortion, and output amplitude must have a minimum of $5 \mathrm{~V}$.

The fifth block is the mixer, which must be balanced. It can be transistorized or not and must be of down converter type. Students have to measure the isolation ratio between ports and the intermodulation noise, besides the Input-Referred 3rd order Intercept Point (IIP3).

Eventually, the sixth block is the FM demodulator, implemented through a Phase Locked Loop (PLL). Students must measure the modulated signal distortion.

Figure 2 - FM receiver blocks diagram.

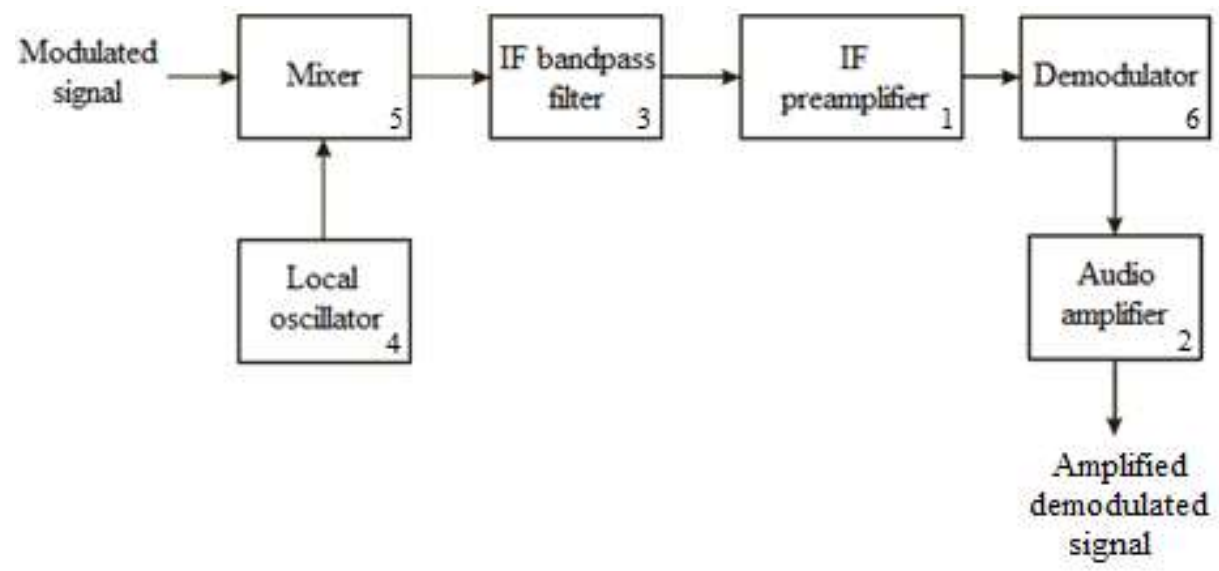

Source: created by the authors (2020).

\section{PBL EFFICIENCY}

The use of PBL in the curriculum of the Communications Circuits discipline had the goal to develop, in the students, skills which will help them to become better prepared professionals to face the new global challenges. Many of these abilities cannot be quantified via standardized tests. One must change his/her traditional thinking about evaluation when 
teaching these new skills. With PBL, students take ownership of the evaluation, including self-evaluation and reflection. Students think about how well or not they worked in a collaborative group and, also, how they contributed, negotiated, listened, and welcomed ideas coming from other team members. They also auto-evaluate their efforts, motivations, interests, and productivity levels, becoming critical, giving constructive feedback one to the others, which help them to be aware of their own strong points and to enhance their interaction with others.

When implementing PBL, one is preparing his/her students to face a new professional reality, giving them a repertoire of skills, which can be successfully used. Besides that, developed PBL projects are of high quality. Students got involved in the tasks of the collaborative projects. They collaborated and solved problems with their teams and worked collectively to foment creativity and to enhance their projects.

Along some semesters, it was possible to observe the student's improvement, as well as upgrade in classes indexes. Three indexes were chosen to evaluate the efficiency of the methodology: registration locking (demanded by the student), failure (in the approval in the discipline) and the class average score. Indexes were analyzed through the comparison of results from 2019 (two semesters having PBL implemented) with results from the three previous years (2016 to 2018, without implementation of PBL).

Figure 3 presents the number of students per class. This variable is almost stable along the semesters, showing almost no variation in the last two years (2018-2019).

Figure 3 - Number of students per semester.

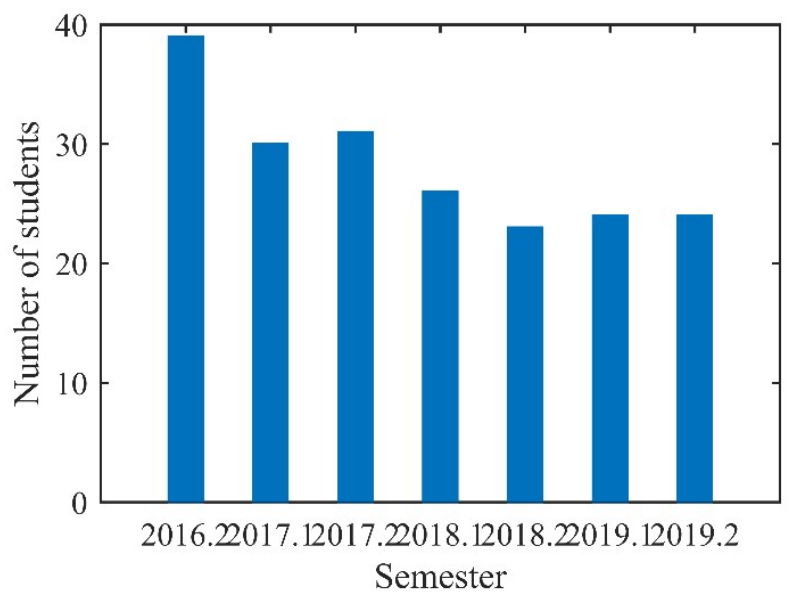

Source: created by the authors (2020).

Figure 4 depicts registration locking. One can observe that this index was higher in the first semesters and then it dropped down, remaining almost zeroed in the last two years (2018-2019). 


\section{(C) COBENGE

Figure 4 - Number of registrations locking per semester.

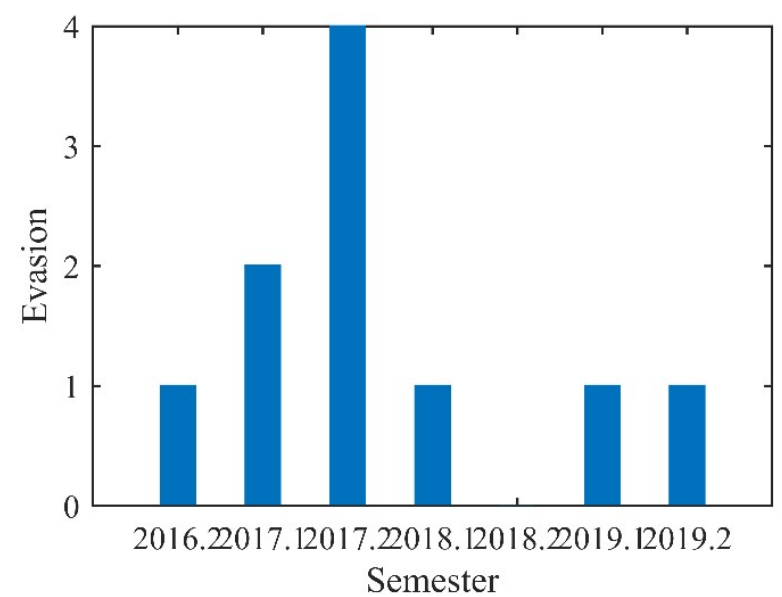

Source: created by the authors (2020).

Figure 5 presents students failure. In the years having the traditional learning methodology, failure was high, reaching $70 \%$ in 2018.1 (first semester of 2018). In the two semesters with PBL implementation, failure fall significatively, being zero in 2019.2. This demonstrates that PBL methodology enhances the interest and the involvement of students in their own learning process.

Figure 5 - Number of failures per semester.

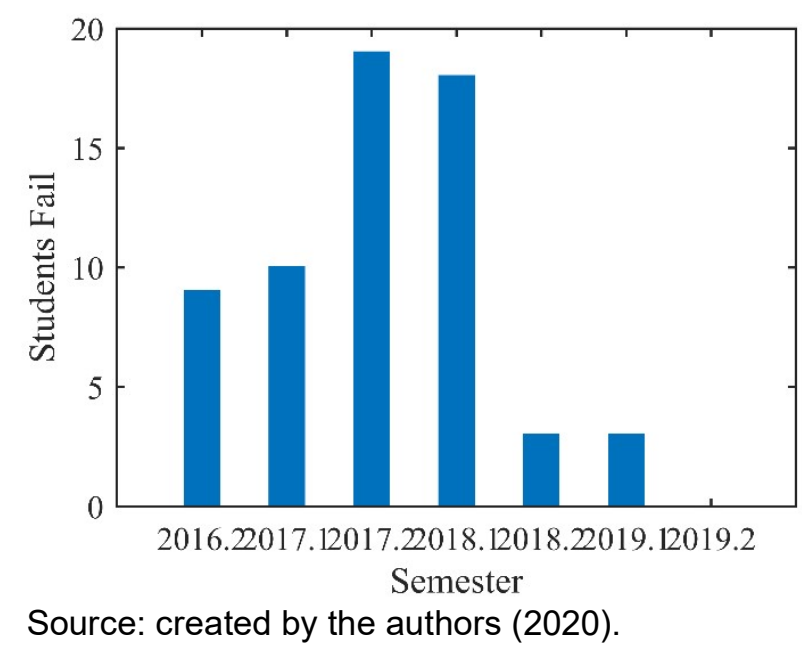

Figure 6 illustrates the classes average score. In the years having the traditional learning methodology, the average score was lower than 6.0 , with a minimum of 2.8 in 2018.1 In the two semesters with PBL implementation the class average score raised, reaching 7.18 in 2019.2. It is one more sign that PBL methodology is stimulating. 
Figure 6 - Classes average score per semester.

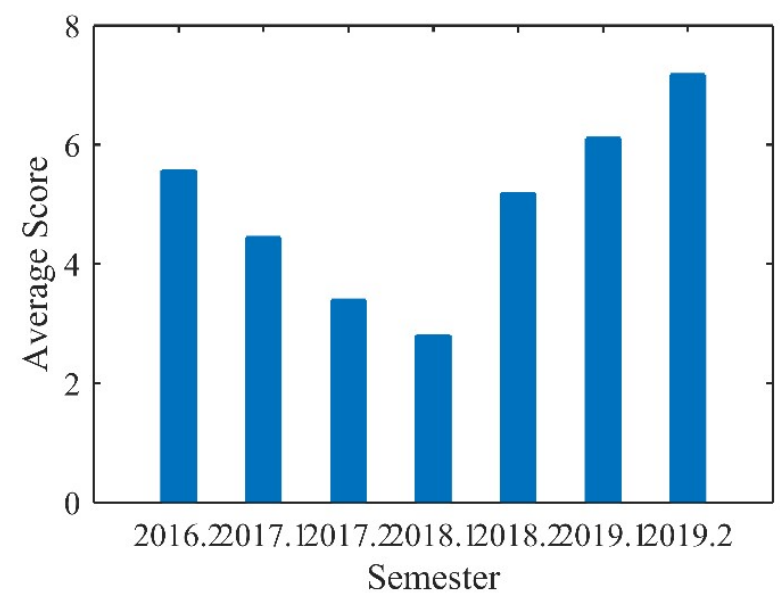

Source: created by the authors (2020).

\section{$7 \quad$ CONCLUSION}

From the results presented herein, one can conclude that the PBL approach is efficient in the incentive to the development of necessary transferable competencies nowadays. In particular, it is observed that students become adepts of teamwork and enhance their communication skills when engaging in practices associated to PBL. More traditional curricula do not necessarily offer this kind of development. As long as pressure increases to redesign courses to reflect the involvement and the current market concerns, PBL can be an appropriate active methodology to guarantee that the adequate attention be given to the curriculum content and to the processes whereby students become effective apprentices. However, proposals must be built with care, so students can catch up an equilibrium between a wide coverage of studied topics and profound studies and analyses.

\section{REFERENCES}

AAS, E. J.; TYPPO, J. Project-Based Learning objectives and experiences in electronic education: a memory controller design experiment. In: 6th IEEE International Conference on Electronics, Circuits and Systems (ICECS'99), 1999, Republic of Cyprus.

BRUCE, J. W.; HARDEN, J. C.; REESE, R. B. Cooperative and progressive design experience for embedded systems. IEEE Transactions on Education, v.47, n.1, p.83-92, February 2004.

COSTA, L. R. J.; HONKALA, M.; LEHTOVUORI, A. Applying the Problem-Based Learning approach to teach elementary circuit analysis. IEEE Transactions on Education, v.50, n.1, p.41-48, February 2007.

ECHAVARRIA, M. V. Problem-Based Learning application in engineering. EIA Magazine, v.7, n.14, p.85-95, 2010. 
HERNANDEZ-JAYO, U.; LÓPEZ-GARDE, J. M.; RODRÍGUEZ-SECO, J. E. Addressing electronic communications system learning through a radar-based active learning project. IEEE Transactions on Education, v.58, n.4, p.1-7, February 2015.

KING, C. J. Restructuring Engineering Education: why, how and when? Journal of Engineering Education, v.101, n.1, p.1-5, 2012.

LEHMANN, M.; CHRISTENSEN, P.; DU, X.; THRANE, M. Problem-Oriented and ProjectBased Learning (POPBL) as an innovative learning strategy for sustainable development in engineering education. European Journal of Engineering Education, v.33, n.3, p.283295, June 2008.

LIDDICOAT, A. A.; PAN, J.; HARRIS, J. G. et al. Work in progress - Enhancing studentlearning through state-of-the-art systems level design and implementation. In: 38th Annual Frontiers in Education Conference, 2008, Saratoga Springs, USA.

MCLOONE, S.; LAWLOR, B.; MEEHAN, A. On Project-Oriented Problem-Based Learning (POPBL) for a first year engineering circuits project. In: 25th IET Irish Signals \& Systems Conference 2014 and 2014 China-Ireland International Conference on Information and Communications Technologies (ISSC 2014/CIICT 2014), p.386-391, 2014, Limerick, Ireland.

MINISTRY OF EDUCATION (MEC). National Curricular Guidelines for the Engineering graduation courses, Brazil, April 2009.

MULONGO, G. Effect of active learning teaching methodology on learner participation. Journal of Education and Practice, v.4, n.4, 2013.

NORTHERN, J. Project-Based Learning for a digital circuits design sequence. In: 2007 IEEE Region 5 Technical Conference, 2007, Fayetteville, USA.

ORTIZ, O.; LEIFFER P. Learning analog electronics through Project-Based Investigation of FM communication circuits. American Society for Engineering Education, 2008. Available in

https://pdfs.semanticscholar.org/f23c/ba20f5d04d553467a07fd725a54bdeea2f83.pdf.

PRICE, A.; RIMINGTON, R.; CHEW, M. T.; DEMIDENKO, S. Project-Based Learning in robotics and electronics in undergraduate engineering program setting. In: Fifth IEEE International Symposium on Electronic Design, Test \& Applications, p.188-193, 2010, Ho Chi Minh City, Vietnam.

PRINCE, M. J.; FELDER, R. M. Inductive teaching and learning methods: definitions, comparisons, and research bases. Journal of Engineering Education, v.95, n.2, p.123138, 2006. 
SOTO-CAMPOS, E. Cooperative project-based experience in digital microelectronic design in a telecommunications engineering environment. In: Technologies Applied to Electronics Teaching (TAEE), p. 44-47, 2012, Vigo, Spain.

WORLD ECONOMIC FORUM. The future of jobs: employment, skills and workforce strategy for the fourth industrial revolution. Global Challenge Insight Report, DavosKlosters, 2016. 